\title{
INTERFACES COMO METACOMUNICAÇÃO: CONTRIBUIÇÃO DA ENGENHARIA SEMIÓTICA NA REPRESENTAÇÃO NO CIBERESPAÇO
}

\author{
INTERFACES COMO METACOMUNICACIÓN: \\ CONTRIBUCIÓN DE LA INGENIERÍA SEMIÓTICA A \\ LA REPRESENTACIÓN EN EL CIBERESPACIO
}

\author{
Miriam Cristina Fava Santos* \\ Silvana Drumond Monteiro**
}

\begin{abstract}
RESUMO
Introdução: A interação no ciberespaço pode ser vista como um processo de indicações recíprocas, em que o designer deve indicar como outra pessoa pode agir. Nesse processo, o sujeito informacional não é um agente passivo, ele é chamado à interpretação. A metacomunicação leva o designer a se preocupar em prever as necessidades levando em conta a visão de quem esse sujeito é, o que ele busca na Interface e por meio dela.

Objetivo: Analisar as Interfaces como Metacomunicação do designer no ciberespaço para identificar a contribuição da Engenharia Semiótica para o designer no processo de significação e representação nas interfaces.

Metodologia: Para efetuar a Análise Documental, utilizou-se a técnica de análise categorial, ou seja, um desmembramento dos signos estáticos, dinâmicos e metalinguísticos da Teoria da Engenharia Semiótica, comparandoos com a divisão triádica dos signos de Peirce (ícone, índice e símbolo) no corpus selecionado: sites da Biblioteca Nacional da Austrália e da Biblioteca do Congresso dos Estados Unidos.

Resultados: Percebeu-se uma maior preocupação do designer da Biblioteca do Congresso dos Estados Unidos para a metacomunicação, pois o designer criou mais rotas e indicações para caminhos que antecipavam as possíveis intenções dos sujeitos informacionais na busca pelo conhecimento.

Conclusões: A Teoria da Engenharia Semiótica contribui com a Ciência da Informação na busca por representar melhor o conteúdo ao trazer o conceito da Interface como Metacomunicação do designer para o sujeito informacional que navega no ciberespaço, ambos mentes interpretadoras e produtoras de conhecimento.

*Mestre em Ciência da Informação pelo Programa de Pós-Graduação em Ciência da Informação da Universidade Estadual de Londrina. E-mail: miriamfava@hotmail.com

**Doutora em Comunicação e Semiótica pela Pontifícia Universidade Católica de São Paulo (PUCSP). Professora Associada da Universidade Estadual de Londrina (UEL). E-mail: silvanadrumond@gmail.com
\end{abstract}

$$
\text { Inf. Inf., Londrina, v. 21, n. 1, p. } 80 \text { - 102, jan./abr. } 2016 .
$$


Palavras-chave: Interfaces. Metacomunicação. Engenharia semiótica. Semiótica. Representação do conhecimento.

\section{INTRODUÇÃO}

Wurman (1991) afirma antes mesmo de o mundo estar inserido no ciberespaço, que a grande crise a ser enfrentada pela sociedade é a de possibilitar que a informação gere compreensão/conhecimento. Esse turbilhão de informações à disposição deveria significar para os sujeitos mais oportunidades de conhecimento, entretanto, para muitos têm representado, frequentemente, mais ansiedade e "[...] uma síndrome da fadiga da informação." (WURMAN, 1991, p. 36). Por isso, a representação do conhecimento no ciberespaço deve ser mais valorizada.

A diversidade semiótica a que somos expostos no dia a dia e também no ciberespaço é apontada por Santaella (2000, p. ix), “[...] pelos emaranhados de sons, imagens, textos, linguagens." A atuação dos signos para representar o conhecimento em uma interface deve promover a semiose, ou seja, o sujeito informacional deve navegar usando das conexões proporcionadas pela interatividade, da percepção e sua cognição, dando a esses signos, significação.

Este trabalho tem suas raízes na teoria Semiótica (PEIRCE, 1977), entendendo que a Semiótica é fundamental para o estudo de fenômenos de comunicação na era digital, vendo a Interface como o mediador digital (ANDERSEN, 1997). Também explora a Teoria da Engenharia Semiótica (EngSem) (SOUZA, 1993) que considera a interface um artefato de metacomunicação, ou seja, uma mensagem é enviada do designer para o sujeito informacional comunicando as funcionalidades e as ações existentes para a interação. Analisa a contribuição desses conceitos para a representação, em um primeiro lugar e, colateralmente, para a produção da semiose no ciberespaço. 


\section{INTERFACES COMO METACOMUNICAÇÃO: A ENGENHARIA SEMIÓTICA}

Quando a Interface homem/computador surgiu, trazia uma linguagem e conceitos técnicos do designer, os quais o sujeito informacional não dominava. Com o uso comercial destes computadores e percebendo as dificuldades para um uso mais autômato dos não especialistas, os designers introduziram metáforas nas interfaces tentando transpor signos do "mundo real" para o "mundo virtual" para uma navegação mais interativa. Dessa forma, a interface adquire ubiquidade e uma função mediadora. Para John Walker (2015) a evolução de Interfaces, em termos de meios de operação do utilizador, é definida por cinco gerações: 1) botões e seletores; 2) cartões perfurados; 3) linha de comandos; 4) sistemas de menus; e 5) interfaces gráficas (controle gráfico e janelas). A Interface Gráfica foi iniciada por Doug Engelbart, quando propôs o princípio das metáforas visuais, que simulava a escrivaninha com suas pastas e documentos. Engelbart também criou o mouse instaurando o princípio da manipulação direta, ou seja, a impressão de que é o sujeito informacional que age ao clicar sobre ícones e ao mover o mouse sobre a tela.

Bruno (2001) exemplifica esse processo de mediação lembrando que as interfaces produzidas "[...] não simplesmente transportam a nossa ação, intenção ou inteligência para uma exterioridade qualquer, mas também produzem sobressaltos que fazem 0 pensamento, 0 homem, a cultura diferir." (BRUNO, 2001, p. 195).

A Arquitetura da Informação (Al) é um termo cunhado por Richard Wurman na década de 1970 que reúne as melhores práticas para uma excelente usabilidade e acessibilidade de informação na Internet, lidando assim com a chamada "ansiedade da informação" sentida pela imensa quantidade de informações proporcionada pelo Ciberespaço.

Oliveira (2014) apresenta quatro abordagens da Arquitetura da Informação: 1) arquitetural; 2) sistêmica; 3) informacional; e 4) pervasiva. A primeira abordagem, a Arquitetural, é voltada aos sistemas 
de informação com enfoque na arquitetura e design. Morville e Rosenfeld (2006) basearam seus estudos em Wurman, para eles a Arquitetura de Informação consiste na combinação entre organização e esquemas de navegação de um sistema de informação, levando em conta as necessidades e hábitos/comportamentos dos sujeitos, 0 conteúdo que será apresentado e o contexto/desenho de uso do sistema, ou seja, o objetivo desses.

A segunda abordagem, a Sistêmica também de Morville e Rosenfeld (2006), define os quatro sistemas interdependentes pelos quais as informações devem ser organizadas: sistema de organização (categorização do conteúdo); de navegação (formas de se mover no espaço informacional); de rotulação (engloba os signos verbais e visuais e de suporte à navegação); e de busca (perguntas que o sujeito informacional pode fazer e respostas que irá obter).

Para Vidotti, Cusin e Corradi (2008), a visão sistêmica de Morville e Rosenfeld (2006) apresenta núcleos conceituais relacionados à Ciência da Informação e, por conseguinte, surge a terceira abordagem da Arquitetura da Informação citada por Oliveira (2014), a Informacional, a qual incide no conteúdo e nas categorias que utilizam para facetá-los. Esses núcleos conceituais são explicitados por Oliveira (2014, p. 104) sendo: "[...] propriedade, formato, estrutura, metadados, volume e dinamismo [...]", que descrevem os conteúdos de forma significativa com o objetivo de "[...] facilitar a recuperação dos recursos disponíveis nos ambientes de informação digital."

O aprofundamento teórico sobre a Arquitetura da Informação considerando as demandas de Pervasividade foi realizado por Oliveira em sua Tese de Doutorado intitulada "Arquitetura da Informação Pervasiva: contribuições conceituais". Esse estudo recebeu a "[...] influência da abordagem sistêmica e amplia a visão da Arquitetura da Informação incorporando conceitos da abordagem informacional." (OLIVEIRA, 2014, p. 99), contribuindo assim para uma construção 
conceitual da Arquitetura da Informação Pervasiva, ou seja, revelando um panorama de emergência dessa abordagem.

Essa quarta abordagem se justifica diante das mudanças tecnológicas, no protagonismo dos sujeitos em ambientes de informação digital e no tipo de experiência que esses ambientes podem fornecer, principalmente quanto à tríade: pervasividade, ubiquidade $\mathrm{e}$ responsividade (OLIVEIRA, 2014, p. 108).

Para Oliveira (2014), a pervasividade é uma categoria mais ampla e refere-se, no contexto da informação, com a qualidade de ser penetrante, extensível, alastrável nos mais diversos dispositivos tecnológicos e incorporável aos comportamentos dos sujeitos. Não há barreiras para o seu acesso.

O autor propõe uma metáfora enquanto recurso didático para a compreensão da tríade, onde uma represa ou barragem com vazamento é vista como a natureza pervasiva da informação, já que "[...] a informação digital invadiu a sociedade e a cultura, de modo que está presente nos espaços, ambientes analógicos e digitais, lugares web e não-web, em diversos tipos de dispositivos e modifica a vida dos sujeitos." (OLIVEIRA, 2014, p. 124). O mesmo acontece quando a água da represa chega às casas e solo, modificando seu estado. Essa incorporação aos múltiplos espaços, ambientes e comportamentos das pessoas remete à ideia de ubiquidade, a informação é ubíqua, ou seja, presente em todos os lugares ao mesmo tempo. Quanto à responsividade, o autor explica que a água será melhor absorvida dependendo das características do material que entra em contato com ela, analogamente a penetração da informação digital nas mais variadas tecnologias disponíveis depende "[...] das características do dispositivo e da capacidade de seus ambientes de informação se moldarem ao contexto e a informação." Dessa forma, "[...] os sujeitos poderão fazer pontes entre esses dispositivos e seus ambientes, mas também poderão não conseguir utilizar [...]." (OLIVEIRA, 2014, p. 125). 
O sistema deve ser projetado baseado nas necessidades e preferências das pessoas para executar diversas tarefas e não o contrário. A compreensão dessas intenções do designer depende de seu conhecimento/habilidade de entender o seu público leitor, o constructo social desse sujeito para apresentar na Interface signos que serão interpretados de maneira a provocar uma verdadeira interação. Sendo assim, deve-se dar importância à representação na Interface para propiciar uma aproximação real.

O designer dessas novas Interfaces deve, mais do que antes, comunicar por que projetou a Interface, o que o sujeito informacional pode fazer por meio dela e o que representa cada signo representado, enfim, deve "metacomunicar", especificar como devem ser interpretados os signos apresentados/reapresentados na Interface (LEITÃO; SILVEIRA; SOUZA, 2013).

Já a Teoria da EngSem é composta pelo: 1) processo de comunicação; 2) o processo de significação; 3) os interlocutores envolvidos; e 4) o espaço de design. Dentre as categorias abordadas pela Teoria da EngSem, o processo de significação teve destaque neste estudo já que envolve os conceitos de signo e semiose, fundamentais para a representação. Albergaria, Bax e Prates (2013, p. 4) definem que o processo de significação "[...] é aquele pelo qual uma determinada cultura associa sistematicamente um conjunto de expressões a um conjunto de conteúdos, que envolve a produção e a interpretação dos signos."

Também envolve compreender quais são os poderes de referência dos signos, que informações transmitem, como se estruturam em sistemas, como funcionam, como são emitidos, produzidos, utilizados e que tipos de efeitos são capazes de provocar no intérprete (SOUZA, 2005). Sendo uma teoria centrada nos fenômenos de significação e comunicação, a representação é parte essencial para que uma Interface possa comunicar, ser compreendida e usada de maneira eficaz e eficiente. 
Focando o design no sujeito informacional, a Engenharia Semiótica permite a ele o entendimento que todo sistema é uma solução potencial de um designer/projetista, pois a interface gráfica é a forma de comunicação do usuário-sistema, por meio de sons, símbolos e ícones. Assim, ao sentir dificuldades durante sua interação, o leitor pode tentar entender a intenção do designer/projetista e acertar o seu modelo mental, suas bases semióticas.

Nessa busca de representar melhor, a Engenharia Semiótica por intermédio do Método de Inspeção Semiótica analisa os usos dos signos pelo designer/projetista na intenção de se fazer entendido pelo sujeito informacional à busca de conhecimento no ciberespaço. Para isso, deve-se analisar a diversidade de signos que são expostos aos sujeitos informacionais durante a interação com interfaces computacionais: os Signos Estáticos, Dinâmicos e os Metalinguísticos.

O Método de Inspeção Semiótica compreende cinco fases de análise e não foi utilizado como método para esse trabalho, utilizou-se, apenas, das categorias dos signos elencadas por ele.

\section{REPRESENTAÇÃO E A SEMIÓTICA}

O ciberespaço com suas características pervasivas, híbridas e fluídas exige das Interfaces uma melhor representação sígnica. Caixeta e Souza (2008, p. 35) afirmam que as atividades dos profissionais da Ciência da Informação revelam a necessidade de representação "[...] para que seja possível a comunicação de subjetividades [...]", por isso entendem que a Ciência da Informação é "[...] eminentemente, uma ciência da representação [...]". Estes autores também ressaltam que o "[...] sucesso de toda a parafernália digital depende da compreensão profunda dos aspectos envolvidos nos processos representacionais." (CAIXETA; SOUZA, 2008, p. 53). Aqui se encontra a percepção/cognição do profissional na representação do conhecimento entendendo qual é a representação "certa" e a "ponte" para que ele seja recebido como útil/relevante e acessível pelo sujeito informacional. 
O termo sujeito informacional considera a complexidade dessa interação e da "[...] percepção da atuação desses sujeitos, enquanto mentes interpretadoras e propositoras de novos arranjos [...]" (ASSIS; MOURA, 2013), marcando a mudança de um usuário passivo para um sujeito dinamizador dos fluxos informacionais. Assis e Moura (2013, p. 86) acrescentam ainda que, por sujeito informacional entende-se um sujeito social "pragmático, uma vez que constrói suas relações pela via da linguagem e do compartilhamento de significados [...]."

Seguindo esse pensamento, do sujeito como agente interpretador, encontra-se o Interacionismo Simbólico, termo criado por Herbert Blumer. A interação humana tem um papel fundamental para a produção do significado, pois para Blumer (1980) é apenas na interação com outras pessoas que a interpretação de um elemento (signo) pode existir, pois são "[...] produtos sociais, criações elaboradas em e através das atividades humanas em seu processo interativo." (BLUMER,1980, p. 121). A interação no ciberespaço pode ser vista da mesma forma, como esse processo de indicações recíprocas, em que o designer deve indicar como outra pessoa pode agir, não apenas reagir, mas é chamado ao processo de autocomunicação e autointeração dos significados para a ação, interpretando-os.

Para Marcondes (2001, p. 64), "Representação é, desta maneira, um processo ocorrendo na mente de alguém, produzindo nesta mente algo distinto do objeto a que se refere. A representação então relaciona o objeto que ela representa com a mente que o percebe [...]". Podemos destacar o papel ativo do sujeito informacional, assim como o papel do profissional da informação ao produzir representações no seu contexto, na sua história, dando sentido ao texto, interpretando-o, fazendo inferências e levando em conta as necessidades e preparando um "[...] (meta) texto que vai intermediar o acesso, a identificação e a avaliação de relevância de um usuário com relação ao texto original." (MARCONDES, 2001, p. 63). 
Para Peirce (1839-1914), o interpretante na relação triádica de um signo, constituído de representamen (signo), objeto (referente) e interpretação (interpretante), reveste-se de fundamental importância na representação do conhecimento, pois essa significação, "[...] 0 significado é sempre o mediador entre a representação e o que é referenciado." (PEIRCE apud SOUZA, 2005, p. 41). Da mesma forma, percebe-se essa importância do interpretante na Interface e na interação para a significação, visto que "[...] a consistência entre os interpretantes do designer e dos usuários é a situação ideal [...]" (ALBERGARIA; BAX; PRATES, 2013).

Pensando em sua lógica triádica, Peirce divide a classificação sígnica em três partes: $1^{\text {a }}$ ) em relação à natureza dos signos (a si mesmo); $2^{a}$ ) a relação do signo com seu objeto e $3^{a}$ ) a relação do signo com seu interpretante. Para este estudo deteve-se à segunda tricotomia, que é uma classificação dos signos baseada na sua relação com os seus objetos dinâmicos, sendo assim o signo pode ser um 1) ícone; 2) índice ou 3) símbolo.

\section{METODOLOGIA}

Este estudo é classificado como documental. Segundo Witter (1990, p. 22), "A pesquisa documental é aquela cujos objetivos ou hipóteses podem ser verificados através da análise de documentos bibliográficos ou não-bibliográficos [...]." O termo "documentos" é ampliado por Godoy (1995, p. 21) incluindo "[...] os elementos iconográficos (como, por exemplo, sinais, grafismos, imagens, fotografias, filmes)."

Para a Análise Documental foi realizada uma análise dos signos em categorias delimitadas pela Semiótica, sendo: os ícones, índices e símbolos; e as categorias elencadas pela Teoria da Engenharia Semiótica: Signos Estáticos, Dinâmicos e Metalinguísticos, especificados no quadro 1. Compreendendo o uso desses signos na metacomunicação do designer para o sujeito informacional que navega 
Miriam Cristina Fava Santos, Silvana Drumond Monteiro

Interfaces como metacomunicação: contribuição da engenharia semiótica na representação no ciberespaço

no site da Biblioteca Nacional da Austrália ${ }^{1}$ e no site da Biblioteca do Congresso dos Estados Unidos².

Quadro 1 - As classificações dos signos da Teoria da Engenharia Semiótica e da Teoria Semiótica de Peirce

\begin{tabular}{|c|c|}
\hline Teoria da Engenharia Semiótica & Teoria da Semiótica \\
\hline $\begin{array}{l}\text { Signos Estáticos: independem da ação } \\
\text { a) retrato instantâneo da tela } \\
\text { b) referente a um único momento do } \\
\text { tempo }\end{array}$ & $\begin{array}{l}\text { İcones/ Hipoícones: qualidade de } \\
\text { sentimento e semelhança com o objeto } \\
\text { Categoria da: potencialidade } \\
\text { possibilidade } \\
\text { independência } \\
\text { qualidade }\end{array}$ \\
\hline $\begin{array}{l}\text { Signos Dinâmicos: interação é } \\
\text { necessária } \\
\text { a) dependem de uma cena interativa } \\
\text { b) estendem-se ao longo de uma } \\
\text { sequência de instantes (vestígios) }\end{array}$ & $\begin{array}{l}\text { İndices: relação de contiguidade física } \\
\begin{aligned} \text { Categoria da: ação e reação } \\
\text { esforço } \\
\text { existência } \\
\text { experiência }\end{aligned} \\
\text { Caráter de indicação }\end{array}$ \\
\hline $\begin{array}{l}\text { Signos Metalinguísticos: explicação } \\
\text { para a ação no sistema } \\
\text { a) signos principalmente verbais } \\
\text { b) comunicam os significados } \\
\text { codificados no sistema }\end{array}$ & $\begin{array}{l}\text { Símbolos: convenção ou lei } \\
\text { Categoria da: mediação } \\
\text { hábito } \\
\text { síntese } \\
\text { processo }\end{array}$ \\
\hline
\end{tabular}

Fonte: Elaborado pelas autoras.

\section{ANÁLISE E RESULTADOS}

Para entender como a metacomunicação do designer ocupa papel central e pode alterar a dinâmica de criação e relação dos signos de uma Interface foi analisado um exemplo de cada signo utilizado nas Interfaces. O primeiro signo estudado é o Signo Estático que foi utilizado para representar a "coleção de informações" nos sites.

\footnotetext{
$1<$ http://www.nla.gov.au/>

$2<$ http://www.loc.gov/>.
} 
Miriam Cristina Fava Santos, Silvana Drumond Monteiro Interfaces como metacomunicação: contribuição da engenharia semiótica na representação no ciberespaço

O designer optou em usar o Signo Estático "collections" para representar as "coleções" que compõem o acervo da Biblioteca Nacional da Austrália na Interface (Figura 1).

Figura 1- Análise do Signo Estático no site da Biblioteca Nacional da Austrália

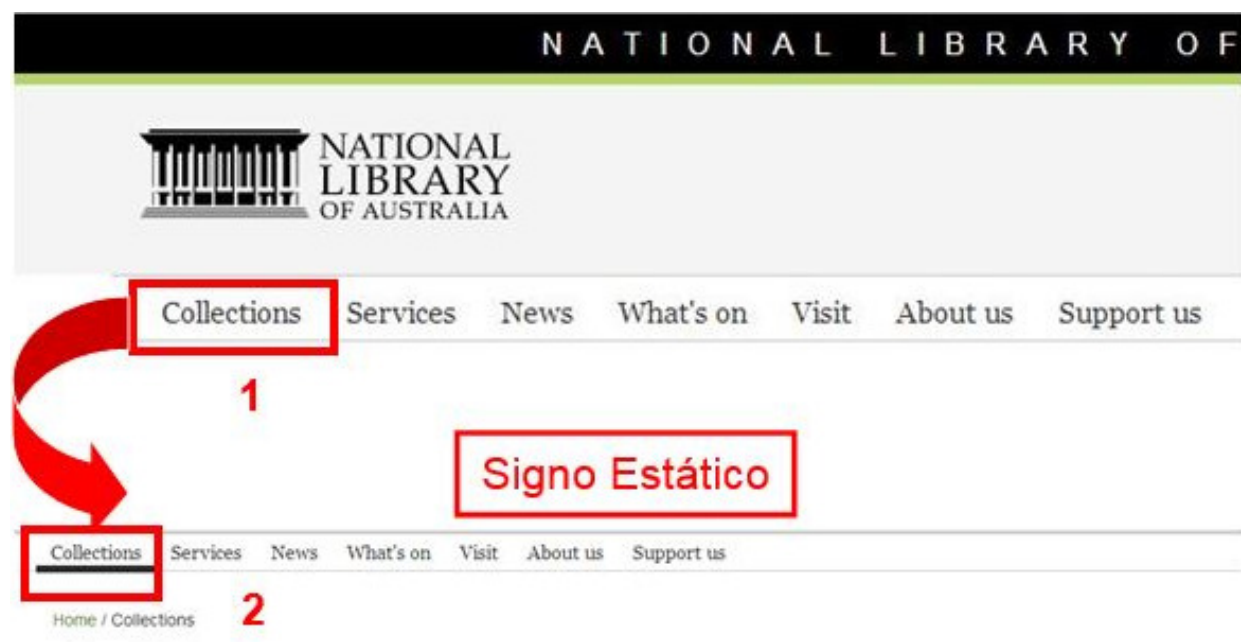

COLLECTIONS

What we collect

The Library holds the greatest collection in the world of material relating to Australia and the Australian people. It ranges from the earliest European works about the Great Southern Land to the most current publications. The collection includes all formats of material, from books and magazines to pictures, photographs, maps, sheet music, oral history recordings, manuscript papers, ephemera and much, much more!
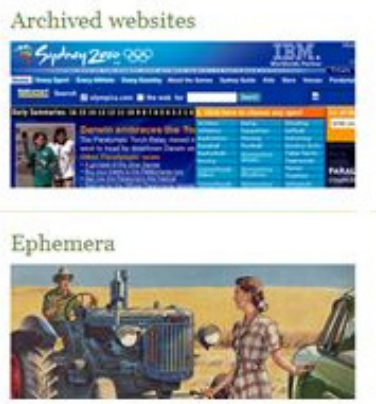
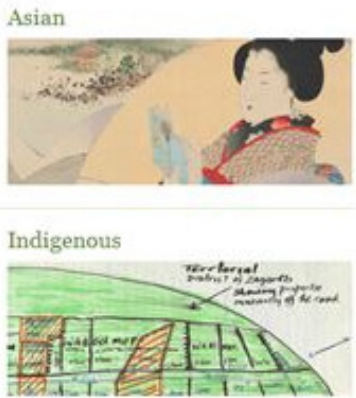
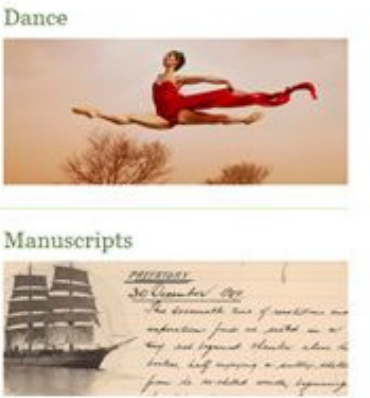

Fonte: Adaptado de National Library of Australia (2015).

O Signo Estático é definido sendo o signo que expressa o estado do sistema e que não necessita de interação do sujeito informacional. No entanto, analisando-o pela Semiótica pode-se ressaltar a sua determinação dupla - Icônica e Simbólica, perceptual e geral. Sua similaridade é produzida por correspondência natural ou por convenção. 
No caso dos Signos Icônicos, esta é uma relação baseada em qualidades (e não em fatos ou regras gerais), e, portanto, as demais relações serão sempre relações baseadas em possibilidade, sugestão, instinto. Sendo assim, embora não possam garantir interpretações sempre consistentes e coerentes, eles propiciam mais novas ideias e novos conhecimentos.

A Interface da Biblioteca Nacional da Austrália exemplifica um designer que entende que o seu sujeito informacional gostaria de obter informações sobre a coleção separadas por categorias (apresentadas por Signos Estáticos).

Quando se seleciona "Collections", o designer disponibiliza a informação por meio de Signos Estáticos, neste momento com o apoio das imagens que apresenta as categorias das coleções da Biblioteca, agindo como Signos Icônicos.

Para comparação analisou-se o signo da Biblioteca do Congresso dos EUA que atua como o "Collections" da Biblioteca Nacional da Austrália. No site da Biblioteca do Congresso dos EUA o signo é representado por "Discover".

Quando se seleciona "Discover" o designer disponibiliza a informação por meio de outros Signos Estáticos, neste momento com o apoio das imagens que apresenta as categorias das coleções da Biblioteca, agindo como Signos Icônicos (Figura 2). 
Miriam Cristina Fava Santos, Silvana Drumond Monteiro Interfaces como metacomunicação: contribuição da engenharia semiótica na representação no ciberespaço

Figura 2 - Análise do Signo Estático no site da Biblioteca do Congresso dos EUA

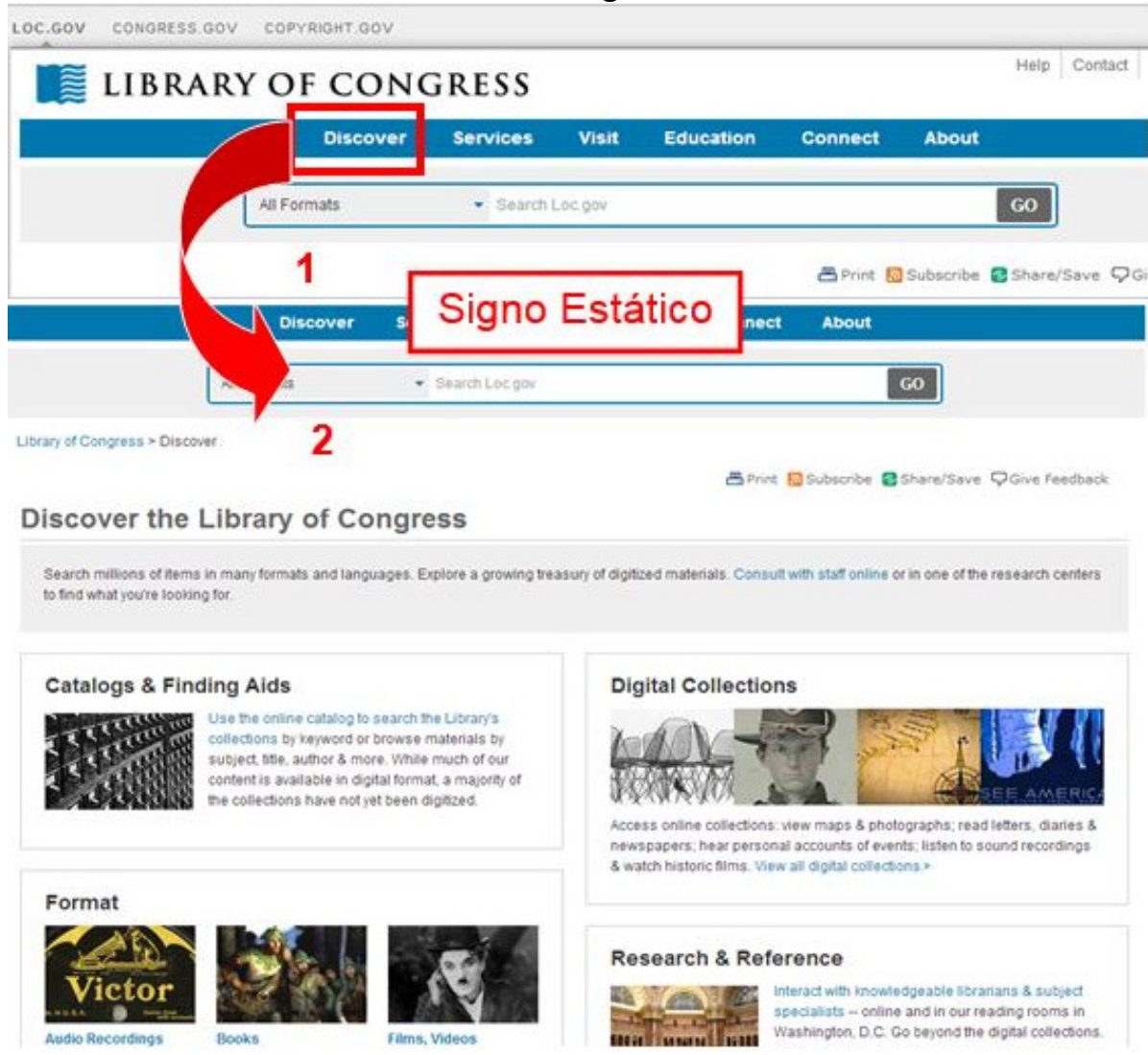

Fonte: Adaptado de Library Of Congress (2015).

$\mathrm{Na}$ Biblioteca dos EUA, o designer oferece ao sujeito informacional a opção de busca dentro da coleção por meio de formatos (apresentado por um Signo Dinâmico), oferece ajuda para a busca da informação por meio de consulta online (apresentada pela consulta à equipe - um Signo Metalinguístico) além de classificar as informações da coleção separadas por categorias (apresentadas por Signos Estáticos).

Percebe-se uma maior preocupação do designer da Biblioteca dos EUA em dialogar com o sujeito informacional indicando mais caminhos que possam levá-lo ao cumprimento da busca por conhecimento.

Ambas Interfaces, a Biblioteca Nacional da Austrália e a Biblioteca do Congresso dos EUA trazem a possibilidade de navegar em sua coleção por intermédio de um Signo Estático. A principal função dos Signos Estáticos é facilitar o reconhecimento visual, eles dependem da 
impressão, do feeling do sujeito informacional durante a navegação, quando agem como Signos Icônicos sugestionam similaridades, dando uma perspectiva utilitária e rápida para obtenção de significados imediatos para navegar pela Interface.

O segundo signo estudado nas Interfaces foi o Signo Dinâmico. Para representar o comando "buscar" no site da Biblioteca Nacional da Austrália, o designer utilizou um Signo Dinâmico "Search this site", com o apoio da imagem de uma lupa.

O designer oferece ao sujeito informacional a opção de buscar dentro de uma lista de resultados e por meio de algumas categorias de filtro por formatos (apresentados Signos Dinâmicos). O designer apresenta os resultados, mas é difícil perceber quais os critérios que foram usados para a definição da prioridade nessa apresentação, além de tornar o processo de busca exaustivo e confuso.

Para representar o comando buscar no site da Biblioteca do Congresso dos EUA, o designer utilizou um Signo Dinâmico "Search Loc.Gov", com o apoio da palavra "Go". A diferenciação mais evidente na comparação entre as Interfaces estudadas é que o designer da Interface da Biblioteca dos EUA trouxe possibilidades diferenciadas para uma refinação/mineração mais rápida já que fornece além da busca geral, a possibilidade do sujeito informacional escolher o formato através de outro signo dinâmico "All formats" onde poderá pesquisar: "todos os formatos, livro, vídeos, mapas, etc...".

Essas várias opções continuam após o "clique" no "Go". Sendo assim, o sujeito informacional nessa Interface recebe mais pistas, ou seja, o modelo de interação está permitindo/antecipando a representação das conversas que poderão ser travadas durante a interação. Além disto, percebe-se o esforço do designer nessa metacomunicação imaginando a conversa com o sujeito informacional e assumindo tanto o papel deste quanto o do seu preposto nos atos comunicativos para a concepção da Interface. Projetando signos, como 
um conjunto, considerando o relacionamento de uns com os outros e com as tarefas do sujeito informacional.

Analisando os Signos Dinâmicos utilizados nas Interfaces, pela perspectiva da Teoria Semiótica, percebe-se a sua atuação como Índice, posicionando-se num nível de Secundidade, o qual com seu caráter relacional de ação e reação deve promover dinâmica e continuidade, implicando em indicadores e trilhas de significado na busca pelo conhecimento.

O terceiro signo estudado nas Interfaces foi o Signo Metalinguístico. Para representar as Perguntas Frequentes no site da Biblioteca Nacional da Austrália, o designer utilizou um Signo Metalinguístico "FAQS", apoiado com a imagem do ponto de interrogação. Ao entrar, o sujeito informacional é conduzido para a página trazendo as opções de usar a busca (Signo Dinâmico), de procurar informações pelas perguntas em destaques (Signos Dinâmicos), buscar em tópicos e ainda pela opção de encaminhar uma consulta (Signo Metalinguístico).

A análise do uso do Signo Metaliguístico na Biblioteca do Congresso dos EUA. Em comparação com o designer da Biblioteca da Austrália percebe-se que o designer da Biblioteca do Congresso dos EUA antecipou e possibilitou um diálogo com mais clareza para as possíveis necessidades e dificuldades do sujeito informacional ao navegar pela Interface. O Signo Metalinguístico "Frequently Asked Questions" encaminha para a página onde o designer trouxe a possibilidade de busca, a lista de perguntas mais frequentes, algumas opções de navegação por um novo menu (Signos Estáticos) e as respostas das perguntas ao final da página.

Com o uso do Signo Metalinguístico, a intenção do designer é proporcionar a identificação e a navegação de maneira, sobretudo, dedutiva pelo sujeito informacional dos signos na Interface, privilegiando a objetividade, generalidade levando em consideração o que Pierce 
afirma ser "[...] intimidade prévia com aquilo que o signo denota." (PEIRCE, 1931, CP 8.179).

Tanto o designer como o sujeito informacional conhecem e internalizaram os esquemas gerais, essa interpretação é devida a um hábito associativo, uma lei que leva à associação de ideias ligando o símbolo a seu objeto. Pode-se retornar às premissas do Interacionismo Simbólico as quais baseiam-se em que a sociedade humana é constituída de "seres humanos em ação" e que a sistematização/significação deve estar de acordo com a natureza da ação social/ interação social.

O Interacionismo Simbólico também considera que na interação entre as pessoas, obrigatoriamente, uma deve estar no papel da outra, indicando o que a outra pessoa fará, elaborando tal indício a partir do ponto de vista da mesma. Tal apreensão de papéis constitui o sine qua non da comunicação e da interação simbólica eficaz (BLUMER, 1980).

\section{CONSIDERAÇÕES FINAIS}

Com o apoio do Interacionismo Simbólico percebe-se que o processo interpretativo é constituído em relação aos significados oferecidos pela interação social. Nesse processo, o sujeito informacional não é um agente passivo, já que o ponto culminante para a interpretação é o processo de autocomunicação dos significados pelo sujeito, situação e seu papel na ação. A interação entre os seres humanos é intermediada pelos signos, assim como o relacionamento com o mundo em busca de conhecimento é influenciado por essa relação, por isso, é a experiência que possibilita um maior entendimento da representação.

A representação sempre serviu para mapear o mundo, com suas linguagens diversas: sonora, visual, verbal, matemática, computacional que acontece na utilização de signos. A representação é o ponto crucial do processo informacional e a Ciência da Informação, a Semiótica e a Engenharia Semiótica trazem contribuições relevantes para os 
processos de significação, organização e representação do conhecimento.

O ciberespaço mostra-nos a evolução e a diversidade semiótica, pois está repleto pelo hibridismo de manifestações sígnicas, e com suas características fluídas, imateriais, interativas e flexíveis trouxeram novos desafios para a representação do conhecimento. A interação no ciberespaço pode ser vista como um processo de indicações recíprocas, em que o designer deve indicar como outra pessoa pode agir, não apenas reagir, mas é chamado à interpretação.

A abordagem da Arquitetura da Informação Pervasiva traz o novo contexto para a representação no ciberespaço devido às mudanças tecnológicas, o protagonismo dos sujeitos em ambientes de informação digital e o tipo de experiência que esses ambientes podem fornecer aos sujeitos, principalmente quanto à tríade: pervasividade, ubiquidade e responsividade.

É nesse novo contexto que a contribuição da Engenharia Semiótica, uma abordagem na qual os sistemas computacionais são vistos como artefatos de metacomunicação, onde o designer/projetista envia uma mensagem para o sujeito informacional, cujo conteúdo é a funcionalidade (o que o sujeito informacional pode fazer) e a interatividade (como pode interagir), é vista como relevante para a representação do conhecimento.

A metacomunicação leva o designer a se preocupar em prever as necessidades do sujeito informacional levando em conta a visão de quem esse sujeito é, o que ele busca na Interface e por meio dela. Usa, para isso, uma metamensagem (por meio dos signos) que necessita ser decodificada e interpretada pelo sujeito atribuindo dessa forma significado para uma resposta acertada do modelo mental do designer, percebendo a Interface como mediador.

As Interfaces são mediadores que permitem trocas entre elas e os sujeitos informacionais de forma que ambos não permanecem iguais e se influenciam mutuamente. Sendo assim, o designer dessas 
Interfaces deve, mais do que antes, comunicar ao sujeito informacional porque projetou a Interface do jeito que fez, o que o sujeito informacional pode fazer por meio dela, o que representa cada signo representado, enfim, deve "metacomunicar", especificar e pontuar como devem ser interpretados os signos apresentados/reapresentados na Interface.

A Engenharia Semiótica se utiliza dos signos estáticos, dinâmicos e metalinguísticos para essa metacomunicação do designer para o sujeito informacional. Esses signos em sua atuação se assemelham ao Ícone/hipoícone, Índice e Símbolo da Teoria Semiótica. A metodologia possibilitou a identificação dos signos conforme prescreve a Semiótica e a Engenharia Semiótica e a influência que eles possibilitam para uma navegação mais eficaz.

No corpus da pesquisa, o site da Biblioteca Nacional da Austrália e o site da Biblioteca do Congresso dos EUA, percebeu-se uma maior preocupação do designer desta última Interface para metacomunicar com o sujeito informacional. Essa consideração deve-se a análise de um Signo Estático, um Signo Dinâmico e um Signo Metalinguístico utilizados na página principal de cada Interface, pois o designer criou mais rotas e indicações para caminhos que antecipavam as possíveis intenções dos sujeitos informacionais na busca pelo conhecimento. O objetivo deste trabalho, no entanto, não foi o de realizar uma Inspeção Semiótica nas Interfaces mas, perceber a importância da Interface como metacomunicação do designer, por meio dos Signos Estáticos, Dinâmicos e Metalinguísticos.

A competência no uso dos signos como metacomunicação das intenções e indicações do designer para a ação do sujeito informacional é que possibilitará uma navegação mais eficiente e eficaz, pois a relação sígnica e a semiose acontecem a partir do reconhecimento das representações, ou seja, o processo de semiose do projetista quando projetou a Interface foi compreendido pelo sujeito quando este estava utilizando-a. Dessa forma o modelo projetado pelo designer foi o modelo percebido pelo sujeito informacional. 
Conclui-se que a Teoria da Engenharia Semiótica contribui com a Ciência da Informação na busca por representar melhor o conhecimento ao trazer o conceito da Interface como Metacomunicação do designer para o sujeito informacional que navega no ciberespaço. Entende-se que é essa antecipação das necessidades, esse diálogo do designer com o sujeito informacional que possibilita uma representação mais eficiente no uso dos signos na Interface, assim como uma interpretação com menos frustração e mais semiose.

A contribuição, deste trabalho, em termos teóricos é o de possibilitar à Ciência da Informação a reflexão de novos conceitos que surgem com as características próprias do ciberespaço para uma abordagem da representação do conhecimento com base na Semiótica e na Engenharia da Semiótica. Em termos práticos, o trabalho pode significar a identificação de novas possibilidades na Organização e Representação do Conhecimento levando em conta um novo olhar sobre a Interface, como metacomunicação, e o papel do designer e sujeito informacional como, mentes interpretadoras e produtoras de conhecimento.

\section{REFERÊNCIAS}

ALBERGARIA, Elisa Tuler; BAX, Marcello Peixoto; PRATES, Raquel Oliveira. Interação Humano Computador na Ciência da Informação. In: ENCONTRO NACIONAL DE PESQUISA EM CIÊNCIA DA INFORMAÇÃO -ENANCIB, 14., 2013, Florianópolis. Comunicação Oral... Florianópolis, 2013. Disponível em: <http://enancib.sites.ufsc.br/index.php/enancib2013/XIVenancib/paper/vi ewFile/343/265>. Acesso em: 20 abr. 2014.

ANDERSEN, Peter Bogh. A theory of computer semiotics. Cambridge: Cambridge University Press, 1997. 
ASSIS, Juliana de; MOURA, Maria Aparecida. Folksonomia: a linguagem das tags. Encontros Bibli: Revista Eletrônica de Biblioteconomia e Ciência da Informação, Florianópolis, v. 18, n. 36, p. 85-106, jan./abr. 2013. Disponível em: $<$ https://periodicos.ufsc.br/index.php/eb/article/view/15182924.2013v18n36p85/24523>. Acesso em: 14 out. 2014.

BLUMER, Herbert. A natureza do interacionismo simbólico. In: MORTENSEN, C. D. Teoria da comunicação: textos básicos. São Paulo: Mosaico, 1980. p.119-138.

BRUNO, Fernanda Gloria. Mediação e Interface: incursões tecnológicas nas fronteiras do corpo. In: SILVA, D. F.; FRAGOSO, S. (Org.s).

Comunicação na cibercultura. São Leopoldo, RS: Ed. Unisinos, 2001. p. 191-215. Disponível em: <http://www.ekac.org/USINOSMedlnterface.pdf $>$. Acesso em: 2 dez. 2014.

CAIXETA, Mário; SOUZA, Renato Rocha. Representação do conhecimento: história, sentimento e percepção. Revista Informação \& Informação, Londrina, v. 13, n. 2, p.34-55, jul./dez. 2008. Disponível em: <http://www.uel.br/revistas/uel/index.php/informacao/article/view/1815/16 88>. Acesso em: 12 jun 2014.

GODOY, Arilda Schimdt. Pesquisa qualitativa: tipos fundamentais.

Revista de Administração de Empresas, São Paulo, v. 35, n. 3, p. 2029. maio/jun. 1995. Disponível em: <http://www.producao.ufrgs.br/arquivos/disciplinas/ 392_pesquisa_qualitativa_godoy2.pdf> Acesso em: 30 maio 2014.

LEITÃO, Carla Faria; SILVEIRA, Milene Selbach; SOUZA, Clarisse Sieckenius de. Uma introdução à engenharia semiótica: conceitos e métodos. 2013. Disponível em: <http://www2.serg.inf.pucrio.br/docs/Leitao-Silveira-deSouza-Tutorial-IHC2013.pdf>. Acesso em: 12 mar. 2015.

LIBRARY OF CONGRESS. Disponível em: <https://www.loc.gov/>. Acesso em: 20 mar. 2015.

MARCONDES, Carlos Henrique. Representação e economia da informação. Revista Ciência da Informação, Brasília, v. 30, n. 1, p. 6170, jan./abr. 2001. Disponível em: $<$ http://www.scielo.br/scielo.php?script=sci_arttext\&pid=S0100$19652001000100008 \&$ Ing=en\&nrm=iso >. Acesso em: 20 mar. 2014.

MORVILLE, Peter; ROSENFELD, Louis. Information architecture for the world wide web. 3. ed. Sebastopol, CA: O'Reilly, 2006. NATIONAL LABRARY OF AUSTRALIA. Disponível em: <http://www.nla.gov.au/>. Acesso em: 20 abr. 2015. 
OLIVEIRA, Henry Poncio Cruz de. Arquitetura da informação pervasiva: contribuições conceituais. 2014. 202f. Tese (Doutorado em Ciência da Informação) - Faculdade de Filosofia e Ciências, Universidade Estadual Paulista, Marília, 2014.

PEIRCE, Charles Sanders. Semiótica. Tradução J. Teixeira Coelho. São Paulo: Perspectiva, 1977.

PEIRCE, Charles Sanders. The Collected Papers of Charles Sanders Peirce. 1931. CP 8.179. Disponível em: <http://www.4shared.com/document/oRnzQCug>. Acesso em: 20 abr. 2015. (vol. 1-8, citado CP seguido pelo número do volume e número do parágrafo).

SANTAELLA, Lucia. A teoria geral dos signos: como as linguagens significam as coisas. São Paulo: Pioneira, 2000.

SOUZA, Clarisse Sieckenius de. The semiotic engineering of humancomputer interaction. Cambridge, MA: The MIT Press, 2005.

SOUZA, Clarisse Sieckenius de. The semiotic engineering of user interface languages. International Journal of Man-Machine Studies, London, v. 39, p. 753-773, 1993.

VIDOTTI, Silvana Aparecida Borsetti Gregório; CUSIN, César Augusto; CORRADI, Juliane Adne Mesa. Acessibilidade digital sob o prisma da Arquitetura da Informação. In: GUIMARÃES, José Augusto Chaves; FUJITA, Mariângela Spotti Lopes. Ensino e pesquisa em Biblioteconomia no Brasil: a emergência de um novo olhar. São Paulo: Cultura Acadêmica, 2008.

WALKER, John. Through the looking glass. In: . The autodesk file: bits of history, words of experience. Disponível em: $<$ https://www.fourmilab.ch/ autofile/www/chapter2_69.html\#SECTION00690000000000000000 >. Acesso em: 15 maio 2015.

WITTER, Geraldina Porto. Pesquisa Bibliográfica, Pesquisa documental e Busca de informação. Estudos de Psicologia, Campinas, v.7, n.1, p. 5-30, jan. /jul. 1990.

WURMAN, Richard Saul. Ansiedade de Informação: como transformar informação em compreensão. São Paulo: Cultura Editores Associados, 1991. 
Miriam Cristina Fava Santos, Silvana Drumond Monteiro

Interfaces como metacomunicação: contribuição da engenharia semiótica na representação no ciberespaço

\title{
Title
}

Interfaces as metacommunication: contribution of semiotic engineering in representation in cyberspace

\begin{abstract}
Introduction: The interaction in cyberspace can be seen as a process of reciprocal information, in which the designer should indicate how else can act. In this process, the informational guy is not a passive agent, it is called the interpretation. Metacommunication leads the designer to worry about predicting the needs taking into account the vision of who this guy is, what he seeks in the interface and through.

Objective: To analyze the interfaces as the designer Metacommunication in cyberspace for identify the contribution of Semiotic Engineering for the designer in the process of signification and representation interfaces.

Methodology: To make the Document Analysis, used the categorical analysis technique, or a spin-off of Static signs, Dynamic and Metalinguistic of Theory of Semiotic Engineering, comparing them with the triadic division of signs Peirce (Icon, Index and Symbol) in the selected corpus: National Library of Australia and the Library of Congress.

Results: It was observed a greater concern of the designer of the US Library of Congress to use the metacommunication, because the designer has created more routes and directions to paths that anticipated the possible intentions of informational subjects in the quest for knowledge.

Conclusions: The theory of Semiotic Engineering contributes to the Information Science in the search for better represent the knowledge to bring the concept of interface as Metacommunication designer for informational subject navigating in cyberspace, both interpreters minds and producers of knowledge.
\end{abstract}

Keywords: Interfaces. Metacommunication. Semiotic engineering. Semiotic. Knowledge representation.

\section{Titulo}

Interfaces como metacomunicación: contribución de la ingeniería semiótica a la representación en el ciberespacio

\section{Resumen}

Introducción: La interacción en el ciberespacio puede ser visto como un proceso de información recíproca, en el que el diseñador debe indicar de qué otra manera puede actuar. En este proceso, el tipo de información no es un agente pasivo, se llama la interpretación. Metacomunicación conduce el diseñador que preocuparse por la predicción de las necesidades teniendo en cuenta la visión de quién es este tipo, lo que busca en la interface de la médula.

Objetivo: Analizar las interfaces como el diseñador metacomunicación en el ciberespacio para identificar la contribución de la Ingeniería Semiótica para el diseñador en el proceso de las interfaces de significación y representación.

Metodología: Para hacer el análisis de documentos, que se utiliza la técnica

Inf. Inf., Londrina, v. 21, n. 1, p. 80 - 102, jan./abr. 2016. 
Miriam Cristina Fava Santos, Silvana Drumond Monteiro

Interfaces como metacomunicação: contribuição da engenharia semiótica na representação no ciberespaço

de análisis categórico, o una spin-off de signos estáticas, dinámica y metalingüística de Teoría Semiótica Ingeniería, comparándolos con la división triádica de los signos de Peirce (icono, índice y símbolo) en el corpus seleccionado: Biblioteca National Australia y la Biblioteca del Congreso de Estados Unidos.

Resultados: Se observó una mayor preocupación de diseñador de la Biblioteca del Congreso para usar la metacomunicación ya que el diseñador ha creado más rutas y direcciones de caminos que anticipan las posibles intenciones de temas informativos en la búsqueda del conocimiento.

Conclusiones: La Teoría de la Ingeniería Semiótica contribuye a la Ciencia de la Información en la búsqueda de una mejor representan el contenido para que el concepto de interface como el diseñador de metacomunicación navegación sujetos informativo en el ciberespacio, ambos interpretadoras mentes y productores de conocimiento.

Palabras clave: Interfaces. Metacomunicación. Ingeniería semiótica. Semiótica. Representación del conocimiento.

Recebido: 12.07.2015

Aceito: 03.03.2016

Inf. Inf., Londrina, v. 21, n. 1, p. 80 - 102, jan./abr. 2016. 